\title{
Choice of Renal Replacement Therapy and Role of Haemodialysis in the Intensive Care Unit
}

\author{
Marlies Ostermann \\ King's College London, Guy's \& St Thomas' Hospital \\ United Kingdom
}

\section{Introduction}

Renal replacement therapy (RRT) has become an established component of modern critical care. Approximately $60-70 \%$ of critically ill patients with severe acute kidney injury (AKI) are treated with RRT which represents $\sim 5 \%$ of all intensive care unit (ICU) admissions (Ostermann \& Chang, 2008; Uchino et al., 2005). Thirty years ago, intermittent haemodialysis for the critically ill patient with AKI was typically delivered three times weekly using dialysis machines without accurate volumetric control, acetate-based dialysate and unmodified cellulosic membrane dialysers. Peritoneal dialysis was performed with hard catheters and low dwell volumes. Since then, the types of RRT used in ICU and the available kits have advanced significantly.

Despite its worldwide use, the practice of RRT is variable. The main reasons are differences in expertise of nursing and medical staff, local availability of machines and lack of robust clinical data to support one technique over another (Pannu et al., 2008). Several important aspects related to the management of RRT, including mode, optimal indications and timing are the focus of ongoing discussion and opposing views.

\section{Aims of RRT}

AKI in critically ill patients manifests itself with varying degrees of uraemia, fluid accumulation, acid base disturbance and non-renal dysfunction. The clinical course can be very variable. RRT for AKI is predominantly supportive with the aim to maintain metabolic and volume haemostasis and to prevent uraemic complications and dysfunction of other organs during the critical illness until renal function recovers. It is important that these benefits of RRT are balanced by potential harm, including risks related to central venous access, infections and anticoagulation (Oudemans-van Straaten, 2007).

\section{Practice of RRT}

\subsection{Indications for RRT}

In the setting of chronic kidney disease, the European Best Practice Guidelines recommend starting chronic dialysis when a patient with an estimated glomerular filtration rate (GFR) of $<15 \mathrm{ml} / \mathrm{min} / 1.73 \mathrm{~m}^{2}$ has symptoms or signs of uraemia, fluid overload or malnutrition in spite of medical therapy or before estimated GFR has fallen to 
$<6 \mathrm{ml} / \mathrm{min} / 1.73 \mathrm{~m}^{2}$ in an asymptomatic patient (European Best Practice Guidelines, 2005). The overall aim is to replace renal function. The situation is very different in the acute setting where RRT for AKI is predominantly viewed as organ support until kidney function recovers. Although acute RRT should be started before the onset of any potentially life threatening complications of uraemia, the optimal time and indications remain controversial. Potential benefits of early initiation are more rapid metabolic/uraemic control and more effective prevention and management of fluid overload (Gibney et al., 2008). Some data also suggest that RRT before the onset of severe AKI may attenuate kidney-specific and non-kidney organ injury from acidemia, uremia, fluid overload, and systemic inflammation, and potentially translate into improved survival and earlier recovery of kidney function (Clark et al., 2006; Matson et al., 2004). The obvious counterargument is that early RRT might subject patients who would recover renal function with conservative treatment alone, to the potential risks associated with RRT (Vinsonneau \& Monchi, 2011). Delay of RRT until AKI is severe avoids treatment in patients with potentially recoverable AKI but increases the risk of uraemic complications and fluid overload.

\subsubsection{Indicators for initiation of RRT}

Studies exploring the optimal indication for starting RRT have used different parameters, including arbitrary cut-offs for serum creatinine, serum urea or urine output, fluid balance, time from ICU admission or time after onset of AKI. Several retrospective studies have shown an association between lower serum urea levels at time of RRT and better outcomes (Gettings et al., 1999; Liu et al., 2006; Shiao et al., 2009). Liu et al reported a lower mortality in 122 patients in a mixed ICU who had serum urea levels $\leq 27 \mathrm{mmol} / \mathrm{L}(\leq 76 \mathrm{mg} / \mathrm{dL})$ on the day when RRT was started compared to 121 patients with higher urea values (Liu et al., 2006). When adjusted for age, hepatic failure, sepsis, thrombocytopenia and serum creatinine, the relative risk of death with a higher urea level at time of RRT was 1.85 (95\% CI 1.16 - 2.96). Improved mortality was also reported in other retrospective studies when RRT was instituted with serum urea $<21 \mathrm{mmol} / \mathrm{L}$ (Gettings et al., 1999) or $<23 \mathrm{mmol} / \mathrm{L}$ (Shiao et al., 2009) compared to higher levels. The authors made the conclusion that "early RRT may be better than late RRT". However, 2 larger studies did not find any correlation between serum urea at time of RRT and outcome (Bagshaw et al., 2009; Ostermann \& Chang, 2009). Instead, they showed that patients who had a serum creatinine $<309 \mu \mathrm{mol} / \mathrm{L}$ at time of RRT had a greater risk of dying compared to those with higher serum creatinine levels. Other studies found a better outcome in patients with a shorter time from ICU admission (Payen et al., 2008; Piccinni et al., 2006), a higher urine output at time of RRT (Sughara \& Suzuki, 2004), and a shorter time between onset of AKI and RRT (Ostermann \& Chang, 2009).

Despite the perception that early RRT may be better, the data are conflicting (Bagshaw et al., 2009; Bouman et al., 2002; Demirkilic et al., 2004; Elahi et al., 2004; Gettings et al., 1999; Liu et al, 2006; Ostermann \& Chang, 2009; Payen et al., 2008; Piccinni et al., 2006; Shiao et al., 2009; Sughara et al., 2004). There are only 2 randomized controlled trials (RCTs) exploring the impact of timing of RRT (Bouman et al., 2002; Sughara \& Suzuki, 2004). The majority of data stem from retrospective analyses with different biochemical cut-offs to distinguish between early and late treatment. Therefore, it cannot be excluded that patients in the "early" RRT group simply had less severe AKI and that patients in the "late" group received RRT too late, ie. after the onset of uraemic complications. Finally, the interpretation of non- 
randomized studies is limited by the exclusion of patients who met criteria for early RRT but never received it.

In the largest prospective RCT investigating the role of timing, 106 predominantly cardiac surgical patients with AKI were randomized to three groups: early high-volume continuous venovenous haemofiltration (CVVHF) $(n=35)$, early low-volume CVVHF $(n=35)$ and late low-volume CVVHF $(n=36)$ (Bouman et al., 2002). There were no significant differences in 28 day mortality or duration of AKI between the groups. All hospital survivors recovered renal function except for one patient in the early low volume CVVH group. Of interest, 4 patients in the late arm recovered renal function spontaneously and 2 patients died before the criteria for $\mathrm{CVVH}$ were met. The authors came to the conclusion that there was no significant benefit with either early CVVH or high filtration rates for patients with oliguric AKI. A large retrospective analysis of 1,847 ICU patients treated with RRT for AKI demonstrated that the most important independent risk factors for ICU mortality were mechanical ventilation, associated organ failure, pre-existing chronic health problems, acidosis, oliguria and age (Ostermann \& Chang, 2009). There was no association between serum urea and creatinine at time of RRT and outcome. The paper concluded that the decision to start RRT should depend less on classic renal parameters but more on the clinical status of the patient, degree of acidosis, risk of fluid overload and associated organ failure.

The negative impact of fluid overload is increasingly being recognised (Bouchard et al., 2009; Payen et al., 2008). In a retrospective analysis of 398 ICU patients, Bouchard et al found a significantly higher ICU mortality in patients who had gained $1-20 \%$ or more in body weight between ICU admission and day of RRT compared to patients without any weight gain (Bouchard et al., 2009). Oliguria and fluid overload in the context of AKI should be viewed as triggers for RRT independent of actual serum urea and creatinine results.

In summary, based on the existing data in the literature, the decision when to start RRT should take into account the patient's severity of illness and its trends, degree of fluid overload and number and types of associated organ failure. Individual serum creatinine or urea parameters are not adequate in identifying the optimal time for RRT. Obviously, in patients with a futile prognosis RRT may not be appropriate. In this case, withholding RRT constitutes good end-of life care (Gabbay \& Meyer, 2009).

\subsection{Choice of RRT modality}

Current RRT options for ICU patients with AKI are continuous modes [continuous haemofiltration (CVVHF), continuous haemodialysis (CVVHD) and continuous haemodiafiltration (CVVHDF)], intermittent haemodialysis (HD), hybrid techniques like slow extended haemodialysis (SLED) or prolonged intermittent renal replacement therapy (PIRRT) and acute peritoneal dialysis. Some characteristics of the different modalities are listed in Table 1.

Continuous RRT is often perceived to offer greater cardiovascular stability compared to traditional intermittent HD. However, intermittent techniques have evolved over the last 20 years. HD machines now have accurate fluid balance control modules with real-time indirect assessment of relative changes in blood volume which allow rapid fluid removal with less haemodynamic instability. A switch towards bicarbonate-based dialysate and less bioincompatible membranes, together with a recognition of the importance of higher dialysate sodium concentrations and cooled dialysate have also led to a reduced the risk of 
intradialytic hypotension. Advantages of intermittent HD are the reduced need for anticoagulation, lower financial costs and greater flexibility which ultimately allows more time for investigations and therapies, including active rehabilitation. Small solutes such as potassium are removed more efficiently with HD which may be particularly beneficial in the setting of acute life threatening hyperkalaemia.

\begin{tabular}{|l|c|c|c|c|c|c|}
\hline & CVVH & CVVHD & CVVHDF & $\begin{array}{c}\text { Intermittent } \\
\text { HD }\end{array}$ & $\begin{array}{c}\text { SLED / } \\
\text { PIRRT }\end{array}$ & PD \\
\hline Solute transport & Convection & Diffusion & $\begin{array}{l}\text { Convection } \\
\text { + diffusion }\end{array}$ & Diffusion & Diffusion & Diffusion \\
\hline $\begin{array}{l}\text { Therapy } \\
\text { time/day }\end{array}$ & 24 hours & 24 hours & variable & $4-6$ hours & $\begin{array}{l}6-12 \\
\text { hours }\end{array}$ & 24 hours \\
\hline $\begin{array}{l}\text { Blood flow } \\
\text { (ml/min) }\end{array}$ & $100-250$ & $100-250$ & $100-250$ & $200-350$ & $100-300$ & none \\
\hline $\begin{array}{l}\text { Urea clearance } \\
\text { (ml/min) }\end{array}$ & $20-40$ & $25-45$ & $25-45$ & $150-180$ & $90-140$ & $15-35$ \\
\hline $\begin{array}{l}\text { Need for } \\
\text { Anticoagulation }\end{array}$ & Yes & Yes & Yes & $\begin{array}{c}\text { Not } \\
\text { absolutely }\end{array}$ & $\begin{array}{c}\text { Not } \\
\text { absolutely }\end{array}$ & No \\
\hline
\end{tabular}

Table 1. Comparison between different modes of RRT (adapted from Mehta et al., 1993)

In addition to potentially better haemodynamic stability, continuous RRT offers the advantage of more sustained fluid removal and less fluctuations in fluid status and metabolic control. Obvious disadvantages are the need for continuous anticoagulation and less flexibility, including less time for the patient to participate in active rehabilitation. The rate of solute removal is lower than with intermittent HD. Over the last few years, there has been much debate whether haemofiltration offers additional benefits for patients with AKI and severe sepsis / septic shock beyond solute clearance (Peng Z et al., 2010). Proponents argue that RRT in the context of severe sepsis contributes to removal of soluble inflammatory mediators of sepsis and restores immune function through improved antigenpresenting capability and leukocyte responsiveness (Honoré et al., 2007). Although this concept of "blood purification" is conceptually appealing, the evidence is limited to data from animal models and small human studies (Bouman et al., 2007).

Although there are differences in capillary fibre structure and design, most ICUs use the same dialysers for CRRT, PIRRT and IHD. The resurgence of batch dialysis systems (for instance, Genius ${ }^{\circledR}$, NxStage $\left.{ }^{\circledR}\right)$ and the use of individual water purification systems (microfilters, water softeners, multiple pass reverse osmosis) coupled with endotoxin filters has made it possible to provide haemodialysis even without access to ultrapure water supply as in chronic haemodialysis units.

\subsubsection{Continuous versus intermittent RRT}

It is widely perceived that continuous modes may be better for critically ill patients with AKI. However, prospective randomised clinical trials have failed to confirm this. Based on 4 different systematic reviews, there is no convincing evidence that continuous RRT is superior to intermittent HD in terms of mortality or renal recovery (Bagshaw et al., 2008; Kellum et al., 2002; Rabindranath et al., 2007; Tonelli et al., 2002). Although these analyses included different studies of varying methodological quality and size, the authors came to 
similar conclusions. The Hemodiafe Study, a multicenter RCT comparing intermittent HD versus CVVHDF in patients with AKI and multiple-organ dysfunction syndrome (MODS), showed that it is possible to treat almost all critically ill patients with AKI with intermittent $\mathrm{HD}$, provided strict guidelines to improve tolerance and metabolic control are adhered to (Vinsonneau et al., 2006). In the intermittent HD group, haemodynamic stability was maintained by using a high dialysate sodium concentration and dialysate cooled to $35^{\circ} \mathrm{C}$. There was no difference in outcome between both groups.

Despite the lack of data that continuous RRT is superior to intermittent HD with regards to mortality or renal recovery, there is some evidence that fluid overload may be easier to control with continuous RRT compared to intermittent modalities. Retrospective analysis of data collected as part of the Program to improve Care in Acute Renal Disease (PICARD) study showed that patients treated with intermittent RRT continued to gain fluid in the subsequent days in contrast to patients on continuous RRT in whom the fluid balance was significantly better controlled (Bouchard et al., 2009). This observation makes intermittent HD less suitable for patients with major fluid overload and supports the recommendation to use continuous RRT for this patient group (Vanholder et al., 2011).

Comparative studies of continuous and hybrid techniques are limited (Abe et al., 2010; Kielstein et al., 2004; Kumar et al., 2000; Kumar et al., 2004; Marshall et al., 2004). In a small trial, 39 patients were randomised to either CVVHF or 12-hour SLED (Kielstein et al., 2004). Cardiovascular tolerability and urea clearances were equivalent. However, less heparin was needed and acidosis was corrected faster in patients treated with SLED. In another randomised trial in 60 patients, CVVHDF was compared to $6-8$ hours of SLED (Abe et al., 2010). There was no difference in ICU or 30 day mortality but survivors in the SLED group had higher renal recovery rates and a shorter length of stay in ICU.

\subsubsection{Peritoneal dialysis versus continuous RRT}

Acute peritoneal dialysis in the ICU is possible but requires the insertion of a peritoneal dialysis catheter and relies on an intact peritoneum and adequate bowel movement. It is contraindicated in patients with abdominal pathology. Solute clearance and fluid removal are generally less predictable and controllable and may be reduced in patients with impaired mesenteric blood flow. Removal of large volumes of fluid may not be possible with small dwell volumes, especially in the first 2 weeks after insertion of the peritoneal catheter.

There are only limited data comparing peritoneal dialysis to continuous RRT in adults (Gangji et al., 2005; Swartz et al., 2005). In a Vietnamese study in patients with infection associated AKI, CVVHF was superior but the applied peritoneal dialysis strategies were different from current practice (Phu et al., 2002). Another study showed not difference but the clearance delivered by peritoneal dialysis was low (Gabriel et al., 2008).

In summary, analysis of the currently published studies shows no clear advantage of one modality over the other in terms of mortality or renal recovery. The decision regarding type of RRT should take into account the individual patient's clinical condition, medical and nursing expertise, and the availability of RRT machines. Regular education and training of those who provide RRT is essential with emphasis on the characteristics and values of each RRT technique. During the dynamic course of critical illness the type of RRT modality may have to change in response to the varying needs of the patient. Most clinicians choose continuous RRT for patients with cardiovascular compromise, significant fluid overload and multi-organ failure, and an intermittent mode for cardiovascularly stable patients 
(Kanagasundaram, 2007; VA NIH Acute Renal Failure Trial Network et al., 2008) Although the risk of hypotension is increased during intermittent HD, the Hemodiafe study showed that the introduction of a relatively simple treatment algorithm including use of a high dialysate sodium concentration of $145 \mathrm{mmol} / \mathrm{L}$ in combination with cooled dialysate and stopping vasodilator infusions, markedly reduced the risk of intradialytic hypotension (Vinsonneau et al., 2006). Hybrid techniques like SLED / PIRRT offer the advantages of both CRRT and intermittent HD, including haemodynamic stability, increased patient mobility and reduced financial costs.

\subsection{General care}

Severe AKI results in hypercatabolism and altered drug metabolism. Provision of adequate nutrition and attention to drug dosing are essential when looking after patients on RRT. While no particular mode or filter is recommended, it is important to understand the characteristics of these different RRT techniques and potential differences in drug removal. Both, under-treatment and drug toxicity have been reported in patients on RRT.

\section{Conclusions}

RRT is a form of organ support for critically ill patients with AKI. The most commonly used modalities are continuous haemo(dia)filtration and intermittent modes. There is no evidence that one mode is superior to another in terms of mortality or renal recovery. Except for a few specific indications, each modality can be considered a valid RRT option for critically ill patients with AKI. The choice should depend on the patient's clinical condition, medical and nursing expertise and local availability of machines. Intermittent HD is an acceptable option for critically ill patients with AKI, including patients with MODS provided clear guidelines are adhered to in order to prevent haemodynamic instability. For patients with significant fluid overload, continuous RRT appears more appropriate.

It is widely acknowledged that the way RRT is delivered has an impact on quality and outcome of patients with severe AKI. The value of regular education and training of those who deliver RRT, and attention to concurrent interventions (drug dosing, nutrition, fluid management) cannot be emphasized enough. There is a clear role for each different modality in the management of AKI in ICU. RRT should be individualised depending on the patient's varying needs during the critical illness.

\section{References}

Abe, M., Okada, K., Suzuki, M., Nagura, C., Ishihara, Y., Fujii, Y., Ikeda, K., Kaizu, K. \& Matsumoto, K. (2010). Comparison of sustained hemodiafiltration with continuous venovenous hemodiafiltration for the treatment of critically ill patients with acute kidney injury. Artificial Organs, Vol, 34, pp. 331-338

Bagshaw, S.M., Berthiaume, L.R., Delaney, A. \& Bellomo, R. (2008). Continuous versus intermittent renal replacement therapy for critically ill patients with acute kidney injury: a meta-analysis. Critical Care Medicine, Vol. 36, pp. 610-617

Bagshaw, S.M., Uchino, S., Bellomo, R., Morimatsu, H., Morgera, S., Schetz, M., Tan, I., Bouman, C., Macedo, E., Gibney, N., Tolwani, A., Oudemans-van Straaten, H.M., Ronco, C., Kellum, J.A. \& Beginning and Ending Supportive Therapy for the Kidney (BEST Kidney) Investigators (2009). Timing of renal replacement therapy 
and clinical outcomes in critically ill patients with severe acute kidney injury. Journal of Critical Care, Vol. 24, pp. 129-140

Bouchard, J., Soroko, S.B., Chertow, G.M., Himmelfarb, J., Ikizler, T.A., Paganini, E.P., Mehta, R.L. \& Program to Improve Care in Acute Renal Disease (PICARD) Study Group. (2009). Fluid accumulation, survival and recovery of kidney function in critically ill patients with acute kidney injury. Kidney International, Vol. 76, pp. 422427

Bouman, C.S., Oudemans-Van Straaten, H.M., Tijssen, J.G., Zandstra, D.F. \& Kesecioglu, J. (2002). Effects of early high-volume continuous veno-venous hemofiltration on survival and recovery of renal function in intensive care patients with acute renal failure: a prospective, randomized trial. Critical Care Medicine, Vol. 30, pp. 22052211

Bouman, C.S., Oudemans-van Straaten, H.M., Schultz, M.J. \& Vroom, M.B. (2007). Hemofiltration in sepsis and systemic inflammatory response syndrome: the role of dosing and timing. Journal of Critical Care, Vol. 22, pp. 1-12

Clark, W.R., Letteri, J.J., Uchino, S., Bellomo, R. \& Ronco, C. (2006). Recent clinical advances in the management of critically ill patients with acute renal failure. Blood Purification, Vol. 24, pp. 487-498

Demirkiliç, U., Kuralay, E., Yenicesu, M., Cağlar, K., Oz, B.S., Cingöz, F., Günay, C., Yildirim, V., Ceylan, S., Arslan, M., Vural, A. \& Tatar, H. (2004). Timing of replacement therapy for acute renal failure after cardiac surgery. Journal of Cardiac Surgery, Vol. 19, pp. 17-20

Elahi, M.M.,Lim, M.Y., Joseph, R.N., Dhannapuneni, R.R. \& Spyt, T.J. (2004). Early hemofiltration improves survival in post-cardiotomy patients with acute renal failure. European Journal of Cardiothoracic Surgery, Vol. 26, pp. 1027-1031

European Best Practice Guidelines 2 (2005). The initiation of dialysis. Nephrol Dial Transplant, Vol. 20, pp. ix3-ix7

Gabbay, E. \& Meyer, K.B. (2009). Identifying critically ill patients with acute kidney injury for whom renal replacement therapy is inappropriate: an exercise in futility? Nephrology Dialysis Transplantation Plus, Vol. 2, pp. 97-103

Gabriel, D.P., Caramori, J.T., Martim, L.C., Barretti, P. \& Balbi, A.L. (2008). High volume peritoneal dialysis vs daily hemodialysis: a randomized, controlled trial in patients with acute kidney injury. Kidney International Supplement, Vol. 73 (Suppl), pp. S87-S93

Gangji, A.S., Rabbat, C.G. \& Margetts, P.J. (2005). Benefit of continuous renal replacement therapy in subgroups of acutely ill patients: A retrospective analysis. Clinical Nephrology, Vol. 63, pp. 267-275

Gettings, L.G., Reynolds, H.N. \& Scalea, T. (1999). Outcome in posttraumatic acute renal failure when continuous renal replacement therapy is applied early versus late. Intensive Care Medicine, Vol. 25, pp. 805-813

Gibney, N., Hoste, E., Burdmann, E.A., Bunchman, T., Kher, V., Viswanathan, R., Mehta, R.L. \& Ronco, C. (2008). Timing of initiation and discontinuation of renal replacement therapy in AKI: unanswered key questions. Clinical Journal of American Society of Nephrology, Vol. 3, pp. 876-880 
Honoré, P., Joannes-Bovau, O. \& Gressens, B. (2007). Blood and plasma treatments: highvolume hemofiltration - a global view. Contributions to Nephrology, Vol. 156, pp. 371-386

Kanagasundaram, N.S. (2007). Renal replacement therapy in acute kidney injury: An overview. British Journal of Hospital Medicine, Vol, 68, pp. 292-297

Kellum, J.A.,Angus, D.C., Johnson, J.P., Leblanc, M., Griffin, M., Ramakrishnan, N. \& LindeZwirble, W.T. (2002). Continuous versus intermittent renal replacement therapy: a meta-analysis. Intensive Care Medicine, Vol. 28, pp. 29-37

Kielstein, J.T., Kretschmer, U., Ernst, T., Hafer, C., Bahr, M.J., Haller, H. \& Fliser, D. (2004). Efficacy and cardiovascular tolerability of extended dialysis in critically ill patients: A randomized controlled study. American Journal of Kidney Diseases, Vol.43, pp. 342349

Kumar, V.A., Craig, M., Depner, T.A. \& Yeun, J.Y. (2000). Extended daily dialysis: a new approach to renal replacement for acute renal failure in the intensive care unit. American Journal of Kidney Diseases, Vol. 36, pp. 294-300

Kumar, V.A., Yeun, J.Y., Depner, T.A. \& Don, B.R. (2004). Extended daily dialysis vs continuous hemodialysis for ICU patients with acute renal failure: a two year single center report. International Journal of Artificial Organs, Vol. 27, pp. 371-379

Liu, K.D., Himmelfarb, J., Paganini, E., Ikizler, T.A., Soroko, S.H., Mehta, R.L. \& Chertow, G.M. (2006). Timing of initiation of dialysis in critically ill patients with acute kidney injury. Clinical Journal of the American Society of Nephrology, Vol. 1, pp. 915919

Marshall, M.R., Ma, T., Galler, D., Rankin, A.P. \& Williams, A.B. (2004). Sustained lowefficiendy daily diafiltration (SLEDD-f) for critically ill patients requiring renal replacement therapy: towards an adequate therapy. Nephrology Dialysis Transplantation, Vol. 19, pp. 877-884

Matson, J., Zydney, A. \& Honore, P.M. (2004). Blood filtration: new opportunities and the implications of systems biology. Critical Care Resuscitation, Vol, 6, pp. 209-217

Mehta, R.L. (1993). Renal replacement for acute renal failure: matching the method to the patient. Semin Dial, Vol. 6, pp. 253-259

Ostermann, M., Chang, R. \& Riyadh ICU Program Users Group (2008). Correlation between the AKI classification and outcome. Critical Care, Vol. 12, pp. R144

Ostermann, M. \& Chang, R.W.S. (2009). Correlation between parameters at initiation of renal replacement therapy and outcome in patients with acute kidney injury. Critical Care, Vol. 13, pp. R175

Oudemans-van Straaten, H.M. (2007). Primum non nocere, safety of continuous renal replacement therapy. Current Opinion in Critical Care, Vol. 13, pp. 635-637

Pannu, N., Klarenbach, S., Wiebe, N., Manns, B., Tonelli, M. \& Alberta Kidney Disease Network (2008). Renal replacement therapy in patients with acute renal failure: a systematic review. Journal of American Medical Association, Vol. 299, pp. 793-805

Payen, D., de Pont, A.C., Sakr, Y., Spies, C., Reinhart, K., Vincent, J.L. \& Sepsis Occurrence in Acutely Ill Patients (SOAP) Investigators (2008). A positive fluid balance is associated with a worse outcome in patients with acute renal failure. Critical Care, Vol., 12, pp. R74 
Peng, Z., Singbartl, K., Simon, P., Rimmelé, T., Bishop, J., Clermont, G. \& Kellum, J.A. (2010). Blood purification in sepsis: a new paradigm. Contributions to Nephrology, Vol. 165, pp. 322-328

Phu, N.H., Hien, T.T., Mai, N.T., Chau, T.T., Chuong, L.V., Loc, P.P., Winearls, C., Farrar, J., White, N. \& Day, N. (2002). Hemofiltration and peritoneal dialysis in infection associated acute renal failure in Vietnam. New England Journal of Medicine, Vol. 347, pp. 895-902

Piccinni, P., Dan, M., Barbacini, S., Carraro, R., Lieta, E., Marafon, S., Zamperetti, N., Brendolan, A., D'Intini, V., Tetta, C., Bellomo, R. \& Ronco, C. (2006). Early isovolaemic haemofiltration in oliguric patients with septic shock. Intensive Care Medicine, Vol. 32, pp. 80-86

Rabindranath, K., Adams, J., Macleod, A.M. \& Muirhead, N. (2007). Intermittent versus continuous renal replacement therapy for acute renal failure in adults. Cochrane Database Systematic Reviews, Vol. 3, pp. CD003773

Shiao, C.C., Wu, V.C., Li, W.Y., Lin, Y.F., Hu, F.C., Young, G.H., Kuo, C.C., Kao, T.W., Huang, D.M., Chen, Y.M., Tsai, P.R., Lin, S.L., Chou, N.K., Lin, T.H., Yeh, Y.C., Wang, C.H., Chou, A., Ko, W.J., Wu, K.D. \& National Taiwan University Surgical Intensive Care Unit-Associated Renal Failure Study Group (2009). Late initiation of renal replacement therapy is associated with worse outcomes in acute kidney injury after major abdominal surgery. Critical Care, Vol. 13, pp. R71

Sughara, S. \& Suzuki, H. (2004). Early start on continuous hemodialysis therapy improves survival rate in patients with acute renal failure following coronary bypass surgery. Hemodialysis International, Vol. 8, pp. 320-325

Swartz, R.D., Bustami, R.T., Daley, J.M., Gillespie, B.W. \& Port, F.K. (2005). Estimating the impact of renal replacement therapy choice on outcome in severe acute renal failure. Clinical Nephrology, Vol. 63, pp. 335-345

Tonelli, M., Manns, B. \& Feller-Kopman, D. (2002). Acute renal failure in the intensive care unit: a systematic review of the impact of dialytic modality on mortality and renal recovery. American Journal of Kidney Diseases, Vol. 40, pp. 875-885

Uchino, S., Kellum, J.A., Bellomo, R., Doig, G.S., Morimatsu, H., Morgera, S., Schetz, M., Tan, I., Bouman, C., Macedo, E., Gibney, N., Tolwani, A., Ronco, C. \& Beginning and Ending Supportive Therapy for the Kidney (BEST Kidney) Investigators (2005). Acute renal failure in critically ill patients: a multinational, multicenter study. Journal of American Medical Association, Vol. 294, pp. 813-818

VA/NIH Acute Renal Failure Trial Network, Palevsky, P.M., Zhang, J.H., O'Connor, T.Z., Chertow, G.M., Crowley, S.T., Choudhury, D., Finkel, K., Kellum, J.A., Paganini, E., Schein, R.M., Smith, M.W., Swanson, K.M., Thompson, B.T., Vijayan, A., Watnick, S., Star, R.A. \& Peduzzi P. (2008). Intensity of renal support in critically ill patients with acute kidney injury. New England Journal of Medicine, Vol. 359, pp. 7-20

Vanholder, R.,Van Biesen, W., Hoste, R. \& Lameire, N. (2011). Pro/con debate: Continuous versus intermittent dialysis for acute kidney injury: a never-ending story yet approaching the finish? Critical Care, Vol. 15, pp. 204-210

Vinsonneau, C., Camus, C., Combes, A., Costa de Beauregard, M.A., Klouche, K., Boulain, T., Pallot, J.L., Chiche, J.D., Taupin, P., Landais, P., Dhainaut, J.F. \& Hemodiafe Study Group. (2006). Continuous venovenous haemodiafiltration versus 
intermittent haemodialysis for acute renal failure in patients with multiple-organ dysfunction syndrome: a multicentre randomised trial. Lancet, Vol. 368, pp. 379-385 Vinsonneau, C. \& Monchi, M. (2011). Too early initiation of renal replacement therapy may be harmful. Critical Care, Vol. 15, pp. 11 


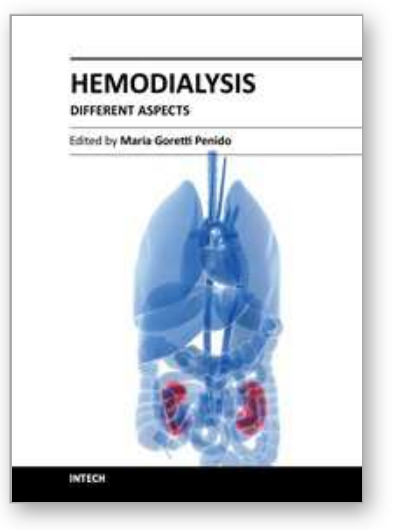

\author{
Hemodialysis - Different Aspects \\ Edited by Prof. Maria Goretti Penido
}

ISBN 978-953-307-315-6

Hard cover, 321 pages

Publisher InTech

Published online 14, November, 2011

Published in print edition November, 2011

The book provides practical and accessible information on all aspects of hemodialysis, with emphasis on dayto-day management of patients. It is quite comprehensive as it covers almost all the aspects of hemodialysis. In short it is a valuable book and an essential aid in the dialysis room.

\title{
How to reference
}

In order to correctly reference this scholarly work, feel free to copy and paste the following:

Marlies Ostermann (2011). Choice of Renal Replacement Therapy and Role of Haemodialysis in the Intensive Care Unit, Hemodialysis - Different Aspects, Prof. Maria Goretti Penido (Ed.), ISBN: 978-953-307-315-6, InTech, Available from: http://www.intechopen.com/books/hemodialysis-different-aspects/choice-of-renalreplacement-therapy-and-role-of-haemodialysis-in-the-intensive-care-unit

\section{INTECH}

open science | open minds

\section{InTech Europe}

University Campus STeP Ri

Slavka Krautzeka 83/A

51000 Rijeka, Croatia

Phone: +385 (51) 770447

Fax: +385 (51) 686166

www.intechopen.com

\section{InTech China}

Unit 405, Office Block, Hotel Equatorial Shanghai

No.65, Yan An Road (West), Shanghai, 200040, China

中国上海市延安西路65号上海国际贵都大饭店办公楼405单元

Phone: +86-21-62489820

Fax: $+86-21-62489821$ 
(C) 2011 The Author(s). Licensee IntechOpen. This is an open access article distributed under the terms of the Creative Commons Attribution 3.0 License, which permits unrestricted use, distribution, and reproduction in any medium, provided the original work is properly cited. 